\title{
Design an Information Management System for a Gas Station
}

\author{
Hewa Majeed Zangana \\ Department of Computer Science / College of Computer Science and IT / Nawroz University / Kurdistan Region of Iraq
}

\begin{abstract}
The management information system for Gas Service Station is developed to facilitate the following areas of operation: profiling of employee and suppliers, point of sale, monitoring of payables, expenditures, sale, and inventory of supplies. Compared to the current system of the company, the system minimizes human error and saves work time. The system generates accurate report as well. It is user friendly and locally networked, operated by one server that updates and records all transactions.
\end{abstract}

Keywords: Automated, Management, Information, Monitoring

\section{INTRODUCTION}

Nowadays, management information systems are needed by the majority of the business organizations because of the increases in complexity and rate of change of today's business environment. An organization that doesn't keep up or have technology driven applications is usually inefficient or unsuccessful.

According to Chowdhury (2008), "inventory system is known to be used by many financial institutions." PIM (Perpetual Inventory Method) system maintains an up-to-date record of accurate level of goods at hand by ensuring that stocks are accounted for at all times, that's why majority of the organizations with the application of information systems are usually easy to manage and all transactions involved are closely monitored.

MIS systems provide a valuable function in that they can collate into coherent reports unmanageable volumes of data that would otherwise be broadly useless to decision makers. By studying these project, decision-makers can identify patterns and trends that would have remained unseen if the raw data were consulted manually. The initial concepts of MIS were to process data from the organization and present them in the form of reports at regular intervals. The system was largely capable of handling the data from collection to processing. It was more impersonal, requiring each individual to pick and choose the processed data and use them for his/her requirements.

Management information systems are used to manage the data created within the structure of a particular business. These systems store the data and allow the business to manipulate, analyze, and compile the data through the use of software applications. Reports and analyses pulled from an information system can assist in the directing, planning, and decision making needs of managers. In the case of Gas Service Station, the business establishment is still under manual operation, which causes data inconsistencies. However, the organization is open for change and development especially in the development of an information system.

According to Hall (2008), management information system uses information technology to carry out the functions of management. It is concerned with information related to people, products, procedures, and technologies. The researcher developed a management information system for Gas Station. The system provides features for point of sale, monitoring, inventory, payables, and purchases.

According to Lawrie (2009), the business case for point of sale replacement sold is dosed on improved capabilities to deliver up sell and cross-sell.

\section{STATEMENT OF THE PROBLEM}

This study sought to address the following problems of Gas Service Station:

- Data recording is manually done resulting in data redundancy. Also, data are hard to retrieve when needed.

- The manager and the owner have difficulties determining daily sales and making an inventory of supplies

- Much of employee' time is used in monitoring supplies, payable accounts, and other transaction records. 


\section{PROPOSED SYSTEM}

The proposed system is as follows:

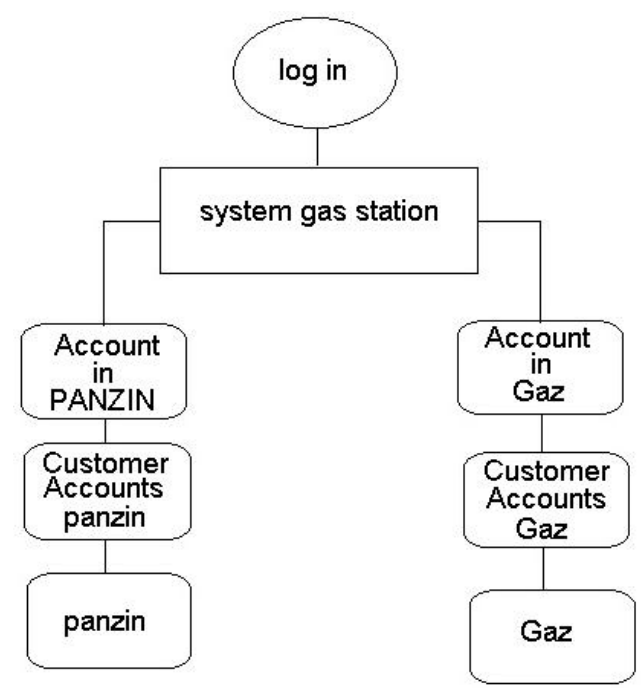

Fig.1: Proposed System

The system for gas station begins like follows:

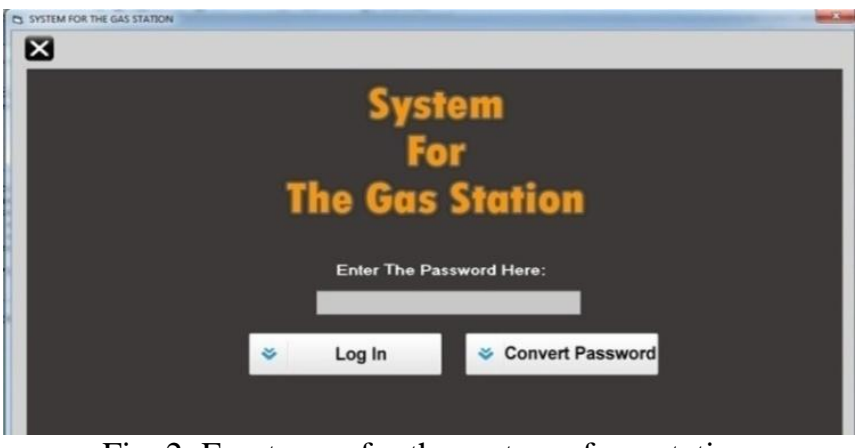

Fig. 2: Front page for the system of gas station

At first running show this form. We can "log in" in our program by this form. This form has two commands and one textbox. First, you should write your password in textbox. If we want to "log in" in program you should click at "log in" command. If you want to change your password you should click at "convert password" command. And if you clicked in "convert password" command the program show you below form

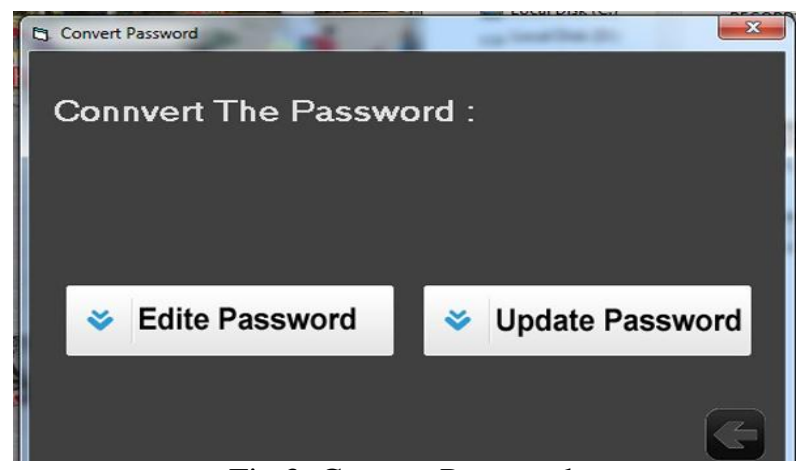

Fig.3: Convert Password

In this form we have two commands "Edit password" and "Update password" .the "Edit password" command used for edit the old password and show you the old password. The "update password" command is used for update old password to new password. 


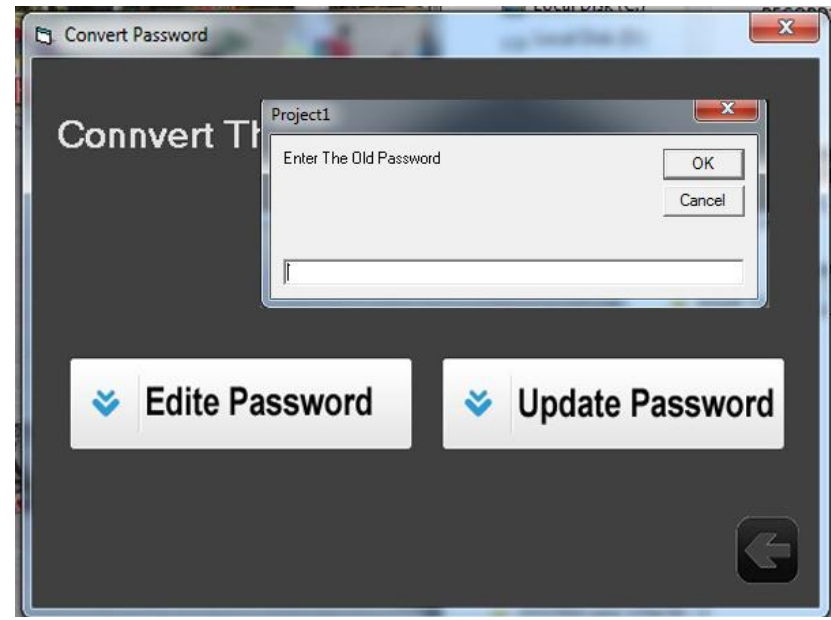

Fig. 4: Update Password

When you clicked on 'Edit Password' the program will show you this message box. You should enter the old password in textbox and then click on 'ok' command that the program show you below form.

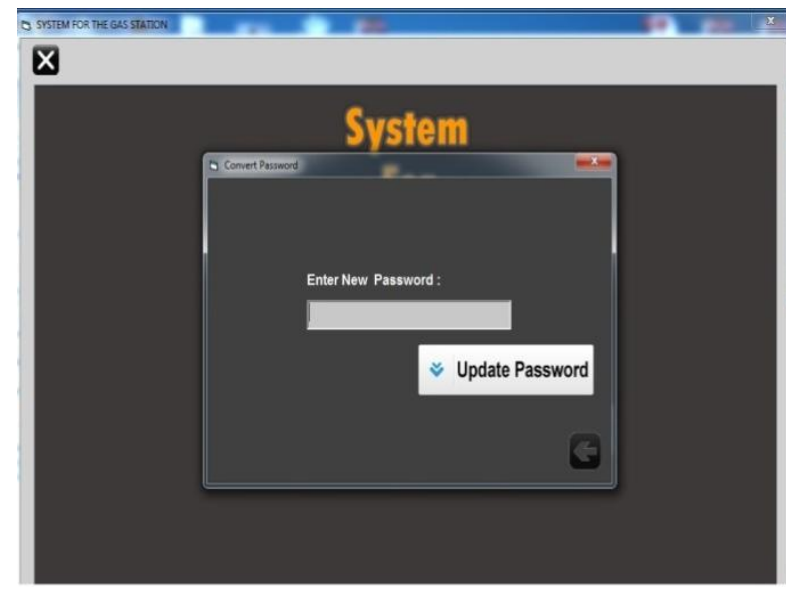

Fig. Edit Password

In this form we have one textbox and one command. In the textbox we can enter the new password and click on 'Update Password' command. When you entered the old password will be changed to new password.

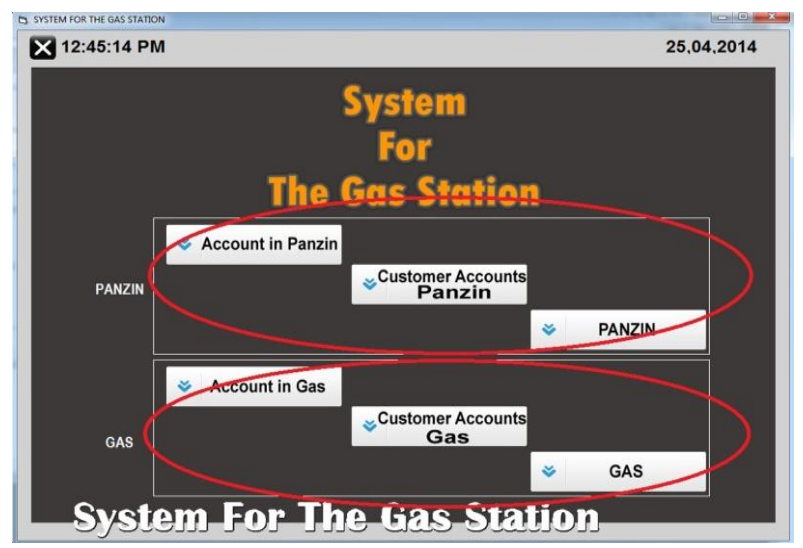

Fig. 5.System gas \& panzin

This form consist of two frames . the first we named by (panzin) and the second by (gas) and each of one contains three commands (from the first fram the account in panzin show you accounting form ,customer account show you customers account.and panzin show panzin s form). (the other form used for the same purpose but for gas). 


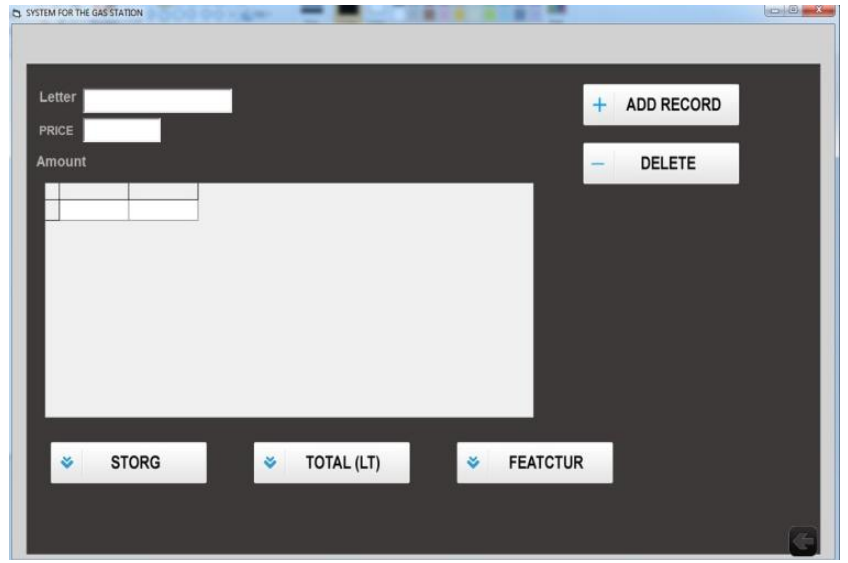

Fig. 6: Account in panzin

This is accounting form. In this form we have two textboxes and six commands and one data grid in "Letter" textbox enter amount of gas by number only and in the "price" textbox enter the price of one letter. And "ADDRCORD" command use for add that information you entered in both textbox and save it in your database. And the "DELETE" command used for delete the record in your database. When you click "STORG" represent that existing data in database at data grid. And the "TOTAL" shows you total letter you have. And the "FEATURD" date of receiving panzin's by (days month year). And "Amount" is a label that show amount. And the arrow command in the bottom used for back to pervious form.

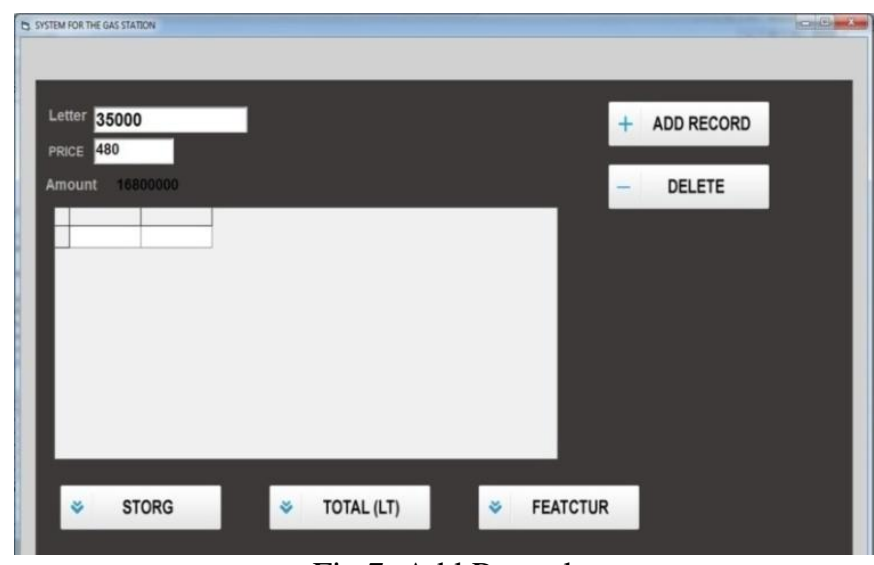

Fig.7: Add Record

The 'ADD RECORD'command used for saving the information you entered in the textbox and save it in the database.

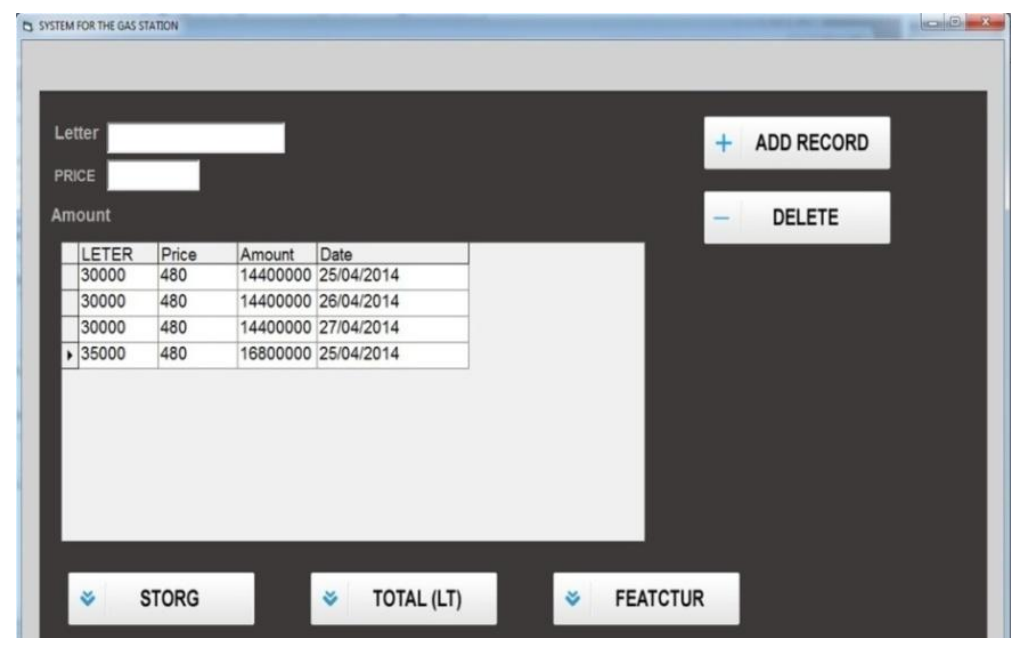

Fig. 8: feature 


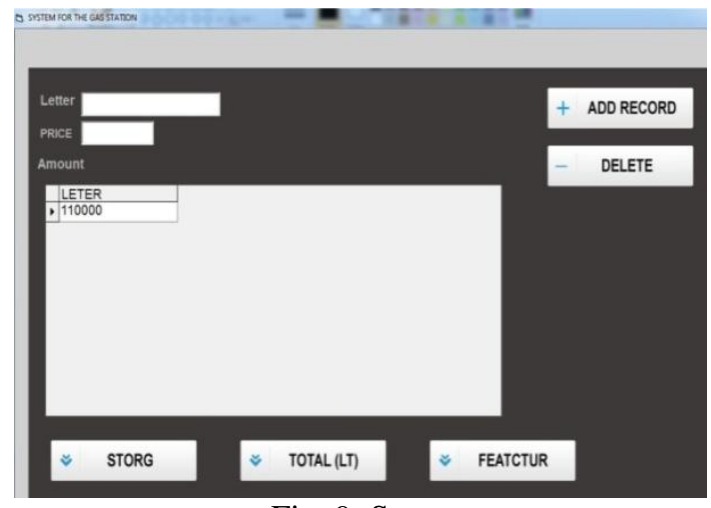

Fig. 9: Store

When you click the store command it will show you that amount you have stored in the storage by liter at the data grid.

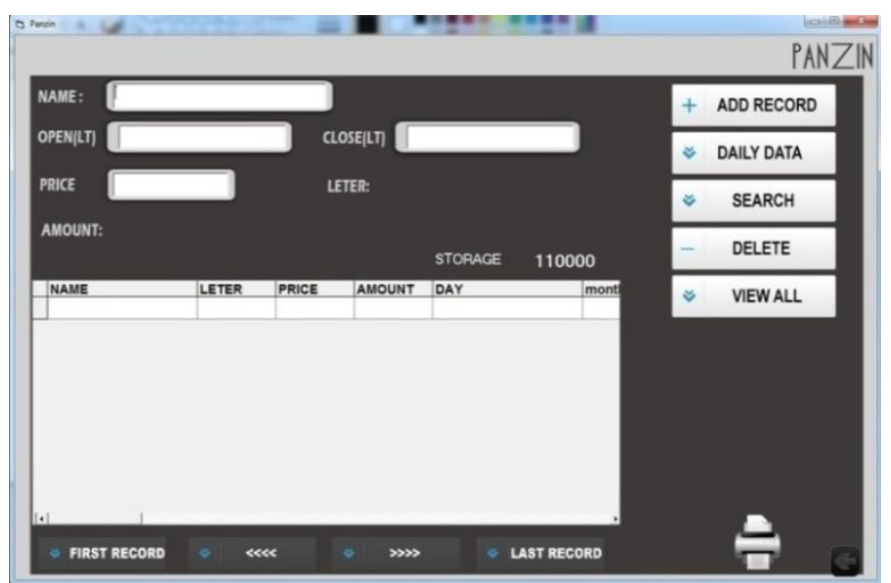

Fig. 10: Customer accounts panzin

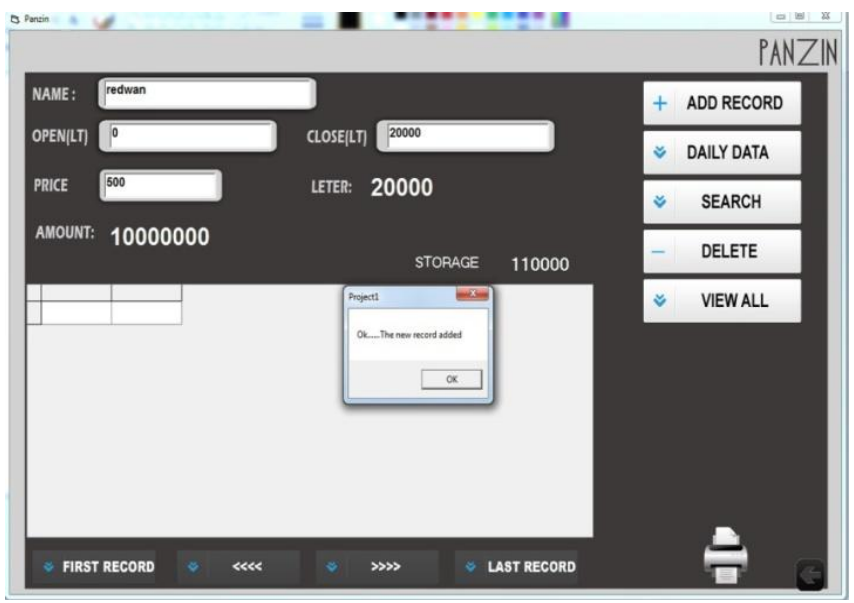

Fig. 11: Customer accounts panzin, Add record

In this form we have four textbox and eleven command and one datagrid. in name's textbox to enter customer's name and in the open's and close's textbox to enter the number of counter. the open textbox to start the work and the close textbox to stop the work. . and the price textbox to enter one panzins litter price. and in this form we have two label the LETER and AMOUNT label the leter's label show you number of liters of panzin's you sell it.and amount's label show total mony. and "ADD RECORD" command used for add that informations you entered in that textbox in the database and save it. and the "DAILYDATA" command used for searching the information daily by entering the date of days you want by date. and "SEARCH" command used for searching the information of each customer you want by entering his name. and "EDIT RECORD" use for edit record .And "VIEW ALL" command represent all information in database at the data grids screen. .that the fourth bottom command used to highlight the name by respectively or by directly. 
The 'ADD RECORD 'command used for save that the information you have been entered in the textbox in the database.

\begin{tabular}{|l|}
\hline $\begin{array}{c}\text { System } \\
\text { For }\end{array}$ \\
ThSTEM FOR THE GAS STATON \\
Thaz Station \\
\hline DATE: 2504/2014 \\
\hline NAME: redwan \\
TOTAL LETERS: 20000 \\
TOTAL AMOUNT: 10000000 \\
PRICE: 500 \\
\hline
\end{tabular}

Fig. 12: Prints Customer accounts panzin

The printer shape command used to show you the information of your choice on the paper.

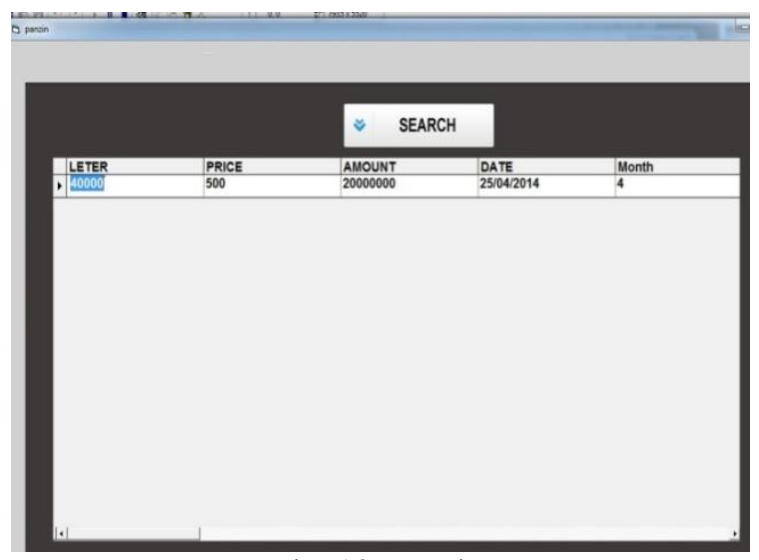

Fig. 13: Panzin

It is panzine's form . in this form we have one command and one datagrid . the search command used for searching information by using month. The datagrid show you the number of litter and price, amount, date and month and the arrow command in the bottom used to back the previouse form.

\section{CONCLUSION}

The management information system for Petron Gas Service Station provides a fast and reliable way of facilitating transactions especially in the monitoring of supplies and payable accounts. The system ensures the security of stored data.

\section{SUGGESTIONS FOR FUTURE WORK}

Base on the findings and conclusion of the study. The following recommendations are advice for the future researchers:

- To include the gasoline price in the monitoring

- To include the companies income

- To include the employees payroll

\section{REFERENCES}

[1]. Database Access Retrieved March 7, 2014 From http://www.vbrad.com/pf.asp?p=Articles/art_binding_evil.htm, retrieved March 7, 2014

[2]. Chowdhury, D 2008 Perpetual Inventory Method (PIM). USA: C \& E Publishing, Inc.

[3]. George Lawrie, The State of Point-of-Sale Systems November 18, 2009 from http://www.forrester.com/rb/Research/state_of_point-ofsale_systems/q/id/54979/t/2

[4]. Kroenke, David 2008 Using MIS - 2nd Edition

[5]. Laudon, K., \&Laudon, J. 2010 Managing the digital firm. (11th ed.). Upper Saddle River, NJ: Pearson Prentice Hall.

[6]. O'Leary, Timothy and Linda. 2008 Computing Essentials Introductory 2008. McGraw-Hill on Computing 2008.com

[7]. O'Sullivan, Ian, and McClure, John. 2010 Get the Job You Want in IT: Insider Strategies for a Successful Job Search Campaign. Signalman Publishing, ISBN 978-0984061471

[8]. Rainer, R. Kelly and Cegielski, Casey G. 2009 Enabling and Transforming Business, 3rd Edition

[9]. Shane Hall. Management Information System. Retrieved March 15, 2014 from http://www.ehow.com/facts_5030594_managementinformation-system theories.html\#ixzz1dprOxYMa. 